\title{
Effects of Renewal SS-cream on the Bulbocavernosus Reflex (BCR) in Rabbits
}

\author{
Long Tian, Yi Guang Wu, Zhe Jin, Yi Chen Zhu, Xin Cheng Qin, Yan Qing Gong and Zhong Cheng Xin* \\ Andrology Center of Peking University First Hospital, Peking University, \\ Institute of Urology Peking University, Beijing, China
}

Renewal SS-cream is a topical agent modified from the original SS-cream which is effective in the treatment of premature ejaculation. In this study, the efficacy of renewal SS-cream on premature ejaculation caused by the bulbocavernosus reflex (BCR) was investigated in rabbits. Sixty male New Zealand white rabbits (weights: $2.5 \sim 3.0 \mathrm{~kg}$ ) were divided into 3 groups randomly. Either renewal or original SS-cream or placebo (provided by CJ Co. LTD) was topically applied to the glans penis of rabbits in a double-blind manner. The bulbocavernosus reflex (BCR) was elicited by electrical stimulation of the glans penis. The latency of BCR (BCRLT) and the amplitude of BCR (BCRAP) were recorded on an electrophysiograph (Poseidomn, Shanghai, China) before and at 10, 30 and $60 \mathrm{~min}$ after application of the test agents. Representative tracings of BCRLT and BCRAP were recorded and analyzed. The mean BCRLT values were significantly prolonged in post-application groups of SS-cream ${ }^{\circledR}$ and renewal SS-cream ${ }^{\circledR}$, compared with those in pre-application and placebo groups $(p<0.05)$. There was no significant difference in efficacy between SS-cream ${ }^{\mathbb{R}}$ and renewal SS-cream ${ }^{\mathbb{R}}$ groups $(p>0.05)$. The mean BCRAP showed decreasing tendency following application of SS-cream ${ }^{\mathbb{R}}$ and renewal SS-cream ${ }^{\mathbb{R}}$; however, they were not significantly different $(p>0.05)$. Both of original SS-cream ${ }^{\circledR}$ and renewal SS-cream ${ }^{\circledR}$ prolonged the BCRLT after their application to the glans penis in rabbits. The results indicate that they have local desensitizing effects on the sensory receptors of the dorsal nerve of the glans penis and may help control the ejaculatory reflex in patients with premature ejaculation.

Keywords: Ejaculation; Reflex; Rabbits

\section{Introduction}

The premature ejaculation $(\mathrm{PE})$ is the most common type of ejaculatory dysfunction; approximately $70 \%$ of men experience PE at some stage of their sexual life. ${ }^{1,2}$ $\mathrm{PE}$ is defined as inability to delay ejaculation sufficiently to enjoy lovemaking and persistent or recurrent occurrence of ejaculation with minimal sexual stimulation be-

Accepted for Publication: October 15, 2008

*Corresponding author: Zhong Cheng Xin, Andrology Center, Peking University First Hospital, Peking University, Phone: +86-10-6611-6161 ext 8808, FAX: +86-10-6618-2822, E-mail: xinzc@bjmu.edu.cn fore, on, or shortly after penetration and before the person wishes it. ${ }^{3,4}$

Different scientific approaches have been used for studying PE; but until now, the precise pathologic mechanisms of PE have remained poorly understood. Traditionally, the cause of PE thought to be psychological in the majority of patients with PE; the proposed causes include anxiety, unresolved conflicts, marital difficulties and infrequent intercourse; and the treatment primarily has involved sex therapy and counseling, including penile-squeeze technique. ${ }^{5-8}$ Recently, neurobiological studies have made it likely that PE is not only a 
psychological disorder but a neurobiological phenomenon. Psychopharmacological treatment studies, animal research data and stopwatch assessments in men with PE indicate that PE is partly a neurobiological phenomenon related to central serotonergic neurotransmission. Although some of psychotropic medications (paroxetine and clomipramine) are highly efficacious for delaying ejaculation; however, these therapies have their limitation because of systemic side effects.

Others and our previous studies had also suggested that patients with $\mathrm{PE}$ showed lower penile sensory threshold and heightened sensory nerve excitability compared with controls ${ }^{9-14}$ and it is significantly reversed by application of a topical agent such as SS-cream ${ }^{\circledR}$ on the glans penis being used for treating PE safe and effective clinically. ${ }^{15-18}$

Renewal SS-cream ${ }^{\circledR}$ is a new topical agent for treating $\mathrm{PE}$, which is made up of main active components of SS-cream ${ }^{\mathbb{R}}$ such as extra ginseng and bufonoid venonum mixed in hydrobase with special enhancer, and renewal SS-cream ${ }^{\mathbb{R}}$ might overcome complaints of some patients on the smell and color of the original SS-cream ${ }^{\circledR}$. Our previous study showed that renewal SS-cream ${ }^{\circledR}$ significantly delayed the latencies of somatosensory evoked potential (SSEP) elicited by electric stimulation of the glans penis, suggesting a local desensitizing effect on the sensory receptor of the dorsal nerveglans penis. ${ }^{19,20}$

In order to further understand the pharmacological action mechanism of renewal SS-cream ${ }^{\circledR}$ on premature ejaculation, and to compare its neurobiological effects with the original SS-cream ${ }^{R}$, the effects of renewal SS-cream ${ }^{\circledR}$ on bulbocavernosus reflex latency (BCRLT) and bulbocavernosus reflex amplitude (BCRAP) in rabbit were investigated.

\section{Materials and Methods}

Renewal SS-cream ${ }^{\circledR}$, original SS-cream ${ }^{\circledR}$ and placebo (provided by CJ Co. LTD) were packaged in same pat- tern $(0.2 \mathrm{mg})$ and coded with allocation numbers. The electrophysiologic recordings were performed using a Poseidomn Electromyograph (Shanghai, China). Sixty male New Zealand White rabbits (weight: $2.5 \sim 3.0 \mathrm{~kg}$ ) were divided into 3 groups, for different drug or placebo application. The "Principles of laboratory animal care" (NIH publication No 86-23, revised 1985) as well as the Chinese goverment rule on the protection of laboratory animals were followed.

\section{BCRLT and BCRAP measurement elicited by glans penis stimuli}

The rabbits were anesthetized with sodium pentobarbital $(50 \mathrm{mg} / \mathrm{kg})$ and fixed in supine position. The glans penis was starched out and put bipolar disk stimulating electrodes on the dorsal of glans and fixed with plastic holder, the anode stimulating electrode was put on the dorsal glans penis and cathode electrode more proximaly with a $2-\mathrm{cm}$ distance on the dorsal penile shaft. The recording concentric needle electrode was inserted into the bulbocavernosus muscle and fixed. Ground electrode was inserted into celiac skin with needle electrode. All eletrodes were connected to electrophysiograph meter.

Rectangular stimuli of $0.1 \mathrm{msec}$ duration were delivered with a stimulus interval of 10 s and stimulation intensity was increased from $2 \mathrm{~mA}$ to $8 \mathrm{~mA}$ until BCR response was induced. The bandpass ranged from $20 \mathrm{~Hz}$ to $10 \mathrm{KHz}$. For each response, the BCRLT between the delivery of stimuli and onset of response was measured by the means of a cursor on the screen. The BCRAP was measured from the baseline to the peak of the BCR wave. Ten consecutive BCR responses were recorded the representative tracing and the mean of these latencies and amplitudes were taken as the final BCRLT value.

\section{Drug application and electromyograph measure- ment procedure}

After connecting the electrodes correctly, the BCR responses were recorded as the blame control. Then the 
test drug or placebos $(0.2 \mathrm{~g})$ were applicated on the glans by massaging mildly for $1 \mathrm{~min}$. Ten to thirty minutes later, BCR and then SSEP were recorded.

The latencies of BCR were measured and recorded by the appendix software. The technician was not allowed access to the information on drugs and the animal. The above protocol was executed in a double-blind manner according to allocation table.

\section{Statistical analysis}

One-Way ANOVA test and Student T-test were utilized and the results were interpreted as statistically significant if the $\mathrm{p}$ value was under 0.05 .

\section{Results}

\section{The BCRLT changes}

Representative tracing of bulbocavernosus reflex (BCR) responses elicited by electric stimulation at the glans penis of rabbit was measured before and after $(10,30$ and $60 \mathrm{~min}$ ) application of renewal SS-cream on glans penis (Fig. 1).

The mean BCRLT were significantly prolonged at 10 , 30 and 60 minutes after application of either of renewal SS-cream and original SS-cream, as compared with the pre-application value and with placebo groups $(\mathrm{p}<$ 0.05); whereas, the placebo group showed no signifi-

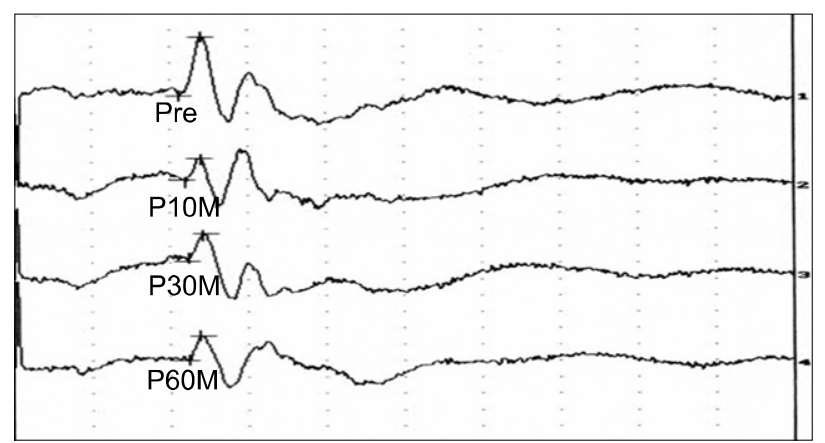

Fig. 1. Representative tracing of bulbocavernosus reflex (BCR) responses elicited by electric stimulation at the glans penis of rabbit before and after (10, 30 and $60 \mathrm{~min}$ ) application of renewal SS-cream ${ }^{\mathbb{R}}$ on glans penis. cant changes $(p>0.05)$. The efficacies of both SS-cream ${ }^{\circledR}$ and original SS-cream ${ }^{\circledR}$ on BCRLT were not statistically different ( $\mathrm{p}>0.05)$ (Fig. 2).

\section{The BCRAP changes}

The results of BCRAP at 10, 30 and 60 minutes after application of either renewal SS-cream ${ }^{\circledR}$ or original SScream $^{\circledR}$ showed decreasing tendency compared with placebo, though statistically insignificant ( $\mathrm{p}>0.05)$ (Fig. 3).

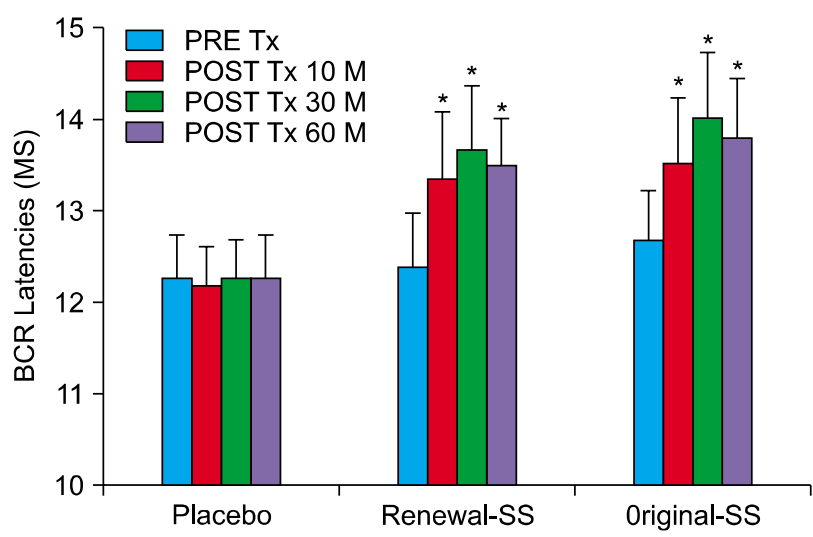

Fig. 2. The latencies of bulbocavernosus reflex (BCRLT) changes elicited by electric stimulation at glans penis of rabbit before (pre) and $10 \mathrm{~min}, 30 \mathrm{~min}, 60 \mathrm{~min}$ after (post) application of test drugs on the glans penis.

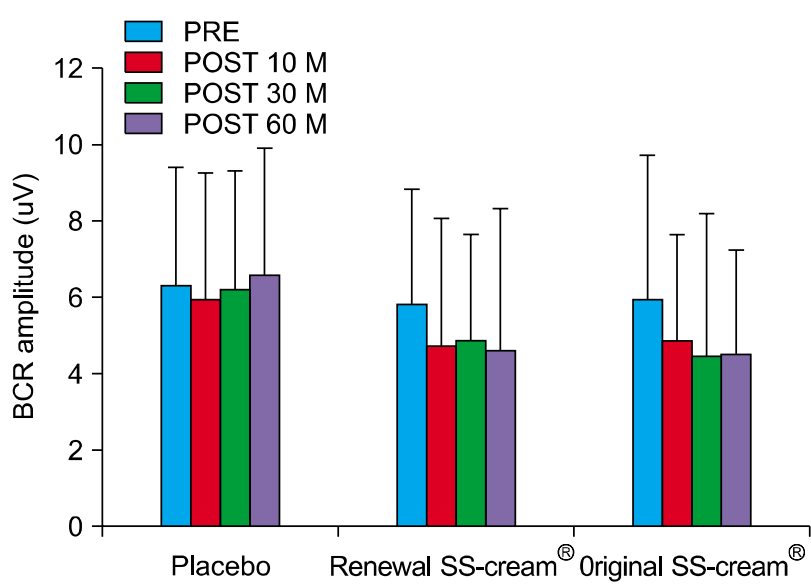

Fig. 3. Amplitudes of bulbocavernosus reflex (BCRAP) measured after electric stimulation at glans penis of different rabbit groups before and 10, 30, 60 min after application of test drugs on the glans penis. 


\section{Discussion}

Premature ejaculation (PE) is a common male sexual dysfunction characterized by the loss or absence of ejaculatory control, marked distress, interpersonal difficulty, and a short intravaginal ejaculatory latency time (IELT). PE can affect the quality of live of both the patient and his partner. Primary treatment has involved psychosexual therapy, with only limited results. Ignorance on the nurophysiological mechanism might have contributed mostly to the unsatisfied treatment of PE.

Ejaculation has three physiological processes. Firstly, the emission is the deposition of seminal fluid components from the ampullary parts of the vasa deferentia, seminal vesicles, and prostate gland into the posterior urethra. Secondly, the ejaculation is the passage of seminal fluid through the urethra and its expulsion from the urethral meatus. The last one, orgasm, is a pleasurable feeling (a cerebral event) usually associated with emission and/or ejaculation. Ejaculation and orgasm constitute the final phase of the sexual response cycle and it is a neurophysiological reflex comprising penile sensory receptors and areas of afferent pathways, cerebral sensory areas, cerebral motor centres, spinal motor centres and efferent pathways. Ejaculation is suggested to be predominantly controlled by a complex interplay between central serotonergic and dopaminergic neurons with secondary involvement of cholinergic, adrenergic, oxytocinergic and GABAergic neurons. Brain and spinal cord mechanisms are integral to the ejaculatory response ${ }^{1,2}$; however, the detailed mechanisms have not been elucidated. Since 1990, various psychopharmacological studies have shown that serotonergic antidepressants may effectively delay ejaculation in men with lifelong premature ejaculation. These results and animal data make it likely that PE is not only a psychological disorder but a neurobiological phenomenon. Although some of psychotropic medications (phenothiazines and antianxiolytics) are effective in delaying ejaculation, these therapies have its limitation because of the unclarified mechanism and systemic side effects. $^{5-8}$

Attempting to elucidate the etiologic bases of PE, we had investigated penile sensory threshold changes in patients with primary $\mathrm{PE}$, and found that patients with $\mathrm{PE}$ showed significantly lower sensory threshold in glans penis compared with normal controls, and latency of somatosensory evoked potentially stimulated at glans penis (GPSEP) was significantly shortened. These results suggested that penile hypersensitivity and/or hyper excitability may be an organic bases of PE. ${ }^{10,15,21}$

SS-cream ${ }^{\circledR}$ is made up of the extracts of 9 natural drugs that showed to have local desensitizing effects. It is safe and effective for treating PE clinically, and the application of SS-cream ${ }^{\circledR}$ on the glans penis increased penile sensory threshold and delayed GPSEP latency significantly. ${ }^{15-17}$

Renewal SS-cream ${ }^{\circledR}$ is a more specifically modified SS-cream ${ }^{\circledR}$, in which the main active components of SS-cream ${ }^{\circledR}$ such as extracts of bufonis venenum and Korean red ginseng were carefully selected and mixed with special enhancer in hydrobase. Previous study showed that renewal SS-cream ${ }^{\circledR}$ significantly inhibited pinprick- induced corneal reflex of rabbits in a dose-dependent manner, demonstrating an excellent local-desensitizing effect. Other previous study indicated that renewal SS-cream ${ }^{\circledR}$ significantly prolonged the latency of SEP of rabbits. ${ }^{20}$

Stimulation of the glans penis evokes contraction of both the bulbocavernosus muscles (BCM) and the external anal sphincter (EAS). This synchronous contraction of the two muscles led us to study their physioanatomic relationship and possible role in erection and ejaculation, and thus, the dorsal nerve somatosensory evoked potential (DNSEP) test and the BCRLT have been used for evaluation of several different superficial peripheral penile sensory nerves, such as the median, ulnar, radial and posterior tibial nerves. ${ }^{18-20,22-24}$

The present study has shown that both the renewal and original SS-cream ${ }^{\mathbb{R}}$ significantly prolonged the BCRLT 10, 30 and 60 min after the application on glans penis of rabbits, and that BCRAP also has decreasing tendency, al- 
though not statistically significant. These results suggested that renewal SS-cream ${ }^{\circledR}$ has the local desensitizing effects on sensory receptor of dorsal never in glans penis, and thus affects the BCR cycle and SEP pathway like original SS-cream ${ }^{\circledR}$. The SEP contribute more to the stumulation of the the cerebral sensory areas during the emission and onset of cerebral ejculation motor center. While BCR cycle might play an important role in contraction of both the BCM and the EAS during the ejaculation movement. These two pathways may help in controlling over ejaculatory reflex in patients with $\mathrm{PE}$. $^{16,17,21,25}$

In this study, the BCR responses to the electric stimulation at the glans penis of rabbit were found to be affected by application of renewal SS-cream ${ }^{\circledR}$ on glans penis, and this methods could serve as a useful aminal model for evaluating ejaculatory dysfunction. The present finding that renewal SS-cream ${ }^{\mathrm{R}}$ showed the significantly delayed BCRLT indicates its local desensitizing effects, suggesting that it could inhibit ejaculatory reflex comprising glans penis sensory receptors and areas, afferent pathway for regulation of ejaculatory reflex and that it may prove effective in treating premature ejaculation.

In conclusion, renewal SS-cream ${ }^{\circledR}$ as well as original SS-cream ${ }^{\circledR}$ has significant local desensitizing effects and may help control ejaculatory reflexes in patients with premature ejaculation. Further clinical study is needed to confirm our findings in rabbit as well as in human.

\section{References}

1. Bush JP. Disorders of ejaculation. In: Bennett AH, ed. Impotence: diagnosis and management of erectile dysfunction. Philadelphia: WB Saunders,1994; 186-96.

2. Godpodinoff ML. Premature ejaculation: clinical subgroups and etiology. J Sex Marital Ther 1989;15:130-4.

3. Strassberg DS, Mahoney JM, Schaugaard M, Hale VE. The role of anxiety in premature ejaculation: a psychophysiological model. Arch Sex Behav 1990;19:251-7.

4. Spector IP, Carey MP. Incidence and prevalence of the sexual dysfunctions: a critical review of the empirical literature. Arch Sex Behavior 1990; 19:389-408

5. Colpi GM, Fanciullacci F, Aydos K, Grugnetti C. Effectiveness mechanism of chlomipramine by neurophysiological tests in subjects with true premature ejaculation. Andrologia 1991;23:45-7.

6. Segraves RT, Saran A, Segraves K, Maguire E. Clomipramine versus placebo in the treatment of premature ejaculation: a pilot study. J Sex Marital Ther 1993;19:198-200.

7. Segraves RT. Effects of psychotropic drugs on human erection and ejaculation. Arch Gen Psychiatry 1989;46:275-84.

8. Waldinger MD, Hengeveld MW, Zwinderman AH. Paroxetine treatment of premature ejaculation: a double-blind, randomized, placebo-controlled study. Am J Psychiatry 1994;151:1377-9.

9. Rowland DL, Haensel SM, Blom JH, Slob AK. Penile sensitivity in men with premature ejaculation and erectile dysfunction. $J$ Sex Marit Ther 1993;19:189-97.

10. Xin ZC, Chung WS, Choi YD, Seong DH, Choi YJ, Choi HK. Penile sensitivity in patients with primary premature ejaculation. $J$ Urol 1996;156:979-81.

11. Breda G, Xausa D, Giunta A, Tamai A, Silvestre P, Gherardi L. Nomogram for penile biothesiometry. Eur Urol 1991;20:67-9.

12. Colpi GM, Fanciullacci F, Beretta G, Negri L, Zanollo A. Evoked sacral potentials in subjects with true premature ejaculation. Andrologia 1986;18:583-6.

13. Fanciullacci F, Colpi GM, Berreta G, Zanollo A. Cortical evoked potentials in subjects with true premature ejaculation. Andrologia 1988; 20:326-30.

14. Henry R, Morales A, Wyllie MG. TEMPE: Topical eutectic-like mixture for premature ejaculation. Expert Opin Drug Deliv 2008;5:251-61.

15. Xin ZC, Choi YD, Seong DH, Choi HK. Sensory evoked potential and effect of SS-cream in premature ejaculation. Yonsei Med J 1995;36:397-401.

16. Xin ZC, Choi YD, Lee SH, Choi HK. Efficacy of a topical agent SS-cream in the treatment of premature ejaculation: preliminary clinical studies. Yonsei Med J 1997;38:91-5.

17. Choi HK, Jung GW, Moon KH, Xin ZC, Choi YD, Lee WH, et al. Clinical study of SS-cream in patients with lifelong premature ejaculation. Urology 2000;55:257-61.

18. Fanciullaci F, Colpi GM, Berretta G, Zanollo A. Cortical evoked potiantials in subjects with true premature ejaculation. Andrologia 1988;20:326-30.

19. Opsomer RJ, Guerit JM, Wese FX, Van Cangh PJ. Pudendal cortical somatosensory evoked potentials. J Urol 1986;135:216-8.

20. Tian L, Xin ZC, Xin H, Fu J, Yuan YM, Liu WJ, et al. Effect of renewed SS-cream on spinal somatosensory evoked potential in rabbits. Asian J Androl 2004;6:15-8.

21. Berkovitch M, Keresteci AG, Koren G. Efficacy of prilocaine-lidocaine cream in the treatment of premature ejaculation. $J$ Urol 1995;154:1360-4.

22. Shafik A. Physioanatomic entirety of external anal sphincter with bulbocavernosus muscle. Arch Androl 1999;42:45-54.

23. Xin ZC, Choi YD, Seong DH, Choi HK. Sensory evoked potential and effect of SS-cream in premature ejaculation. Yonsei Med J 1995;36:397-401.

24. Pescatori ES, Calabro A, Aribani W. Electrical stimulation of dosal nerve of penis evoked reflex tonic erection of penis body and reflex ejaculatory responses in spinal rat. $J$ Urol 1996;149:627-30.

25. Yoshida S, Kamano Y, Sakai T. Studies on the surface anesthetic activity of Bufadienolides isolated from Chan'su. Chem Pharm Bull 1976;24:1714-7. 